\title{
Simple Queue Untuk Manajemen User dan Bandwidth di Jaringan Hotspot Menggunakan Mikrotik
}

\author{
Bambang Kelana Simpony
}

${ }^{1}$ Sistem Informasi, Fakultas Teknik dan Informatika, Universitas Bina Sarana Informatika Jl. Tanuwijaya No.4 Empang Sari Tawang Tasikmalaya, Indonesia e-mail: bambang.bky@bsi.ac.id

$\begin{array}{llll}\text { Informasi Artikel Diterima: 17-11-2020 } & \text { Direvisi: 05-03-2021 } & \text { Disetujui: 08-03-2021 }\end{array}$

\begin{abstract}
Abstrak
Penggunaan bandwidth di jaringan hotspot seringkali kurang dimanfaatkan secara optimal dikarenakan ada beberapa user yang menggunakan layanan internet secara berlebihan sehingga menghabiskan kapasitas bandwidth. Layanan hotspot internet di hotel contohnya sering terjadi tarik menarik bandwidth antar user, terutama layanan internet yang hanya mengandalkan router modem dari penyedia jasa internet. Untuk mengatasai masalah maka perlu dipasang router secara khusus untuk mengatur bandwidth, dalam hal ini menggunakan routerboard dari mikrotik. Dan konfigurasi dengan metode simple queue untuk membagi bandwidth menggunakan winbox. Manajemen bandwidth disesuaikan berdasarkan user yang sudah didaftarkan di router, sehingga koneksi internet lebih stabil. Tidak terjadi lagi tarik menarik bandwidth antar user hotspot. Dampaknya admin jaringan pun dimudahkan dalam memantau akses internet yang dilakukan oleh setiap user.
\end{abstract}

Kata Kunci: bandwidth, mikrotik, simple queue

\begin{abstract}
Bandwidth usage on hotspot networks is often underutilized because there are some users who use internet services excessively, thus consuming bandwidth capacity. Internet hotspot services in hotels, for example, frequent tug-of-war between users, especially internet services that only rely on modem routers from internet service providers. To overcome the problem, it is necessary to install a router specifically to regulate bandwidth, in this case using a routerboard from proxy. And configuration with a simple queue method to divide the bandwidth using winbox. Bandwidth management is adjusted based on users who have registered on the router, so that the internet connection is more stable. No more tug of war between users of hotspots. The impact of the network admin was facilitated in monitoring internet access made by each user.
\end{abstract}

Keywords: bandwidth, mikrotik, simple queue

\section{Pendahuluan}

Internet saat ini menjadi salah satu kebutuhan penting, tidak terkecuali masyarakat di Indonesia. Menurut riset platform manajemen media sosial HootSuite dan agensi marketing sosial We Are Social bertajuk "Global Digital Reports 2020", dijelaskan bahwa di bulan januari 2020, 64 persen penduduk indonesia sudah terkoneksi ke jaringan internet yaitu sekitar 175,4 juta orang, dan mengalami kenaikan sebesar 17 persen dibanding tahun 2019(Kemp, 2020).

Fasilitas internet gratis saat ini bisa ditemui dibeberapa area publik seperti pusat perbelanjaan, restoran dan lain-lain. Internet gratis tetap dapat dijumpai di beberapa tempat meskipun saat ini masyarakat juga sudah terkoneksi internet secara mobile menggunakan jaringan 4G. Tidak terkecuali di Hotel Ramayana Tasikmalaya menyediakan fasilitas internet gratis untuk tamu yang datang ke hotel tersebut. Besar bandwidth yang dimiliki seharusnya sudah cukup, tetapi router yang digunakan hanya terbatas menggunakan router dari Internet Service Provider yang memiliki keterbatas fitur. Sehingga seringkali layanan internet tidak stabil. Bandwidth merupakan jumlah konsumsi transfer data yang dihitung dalam satuan bit per second (bps)(Yasin K, 2018).

Kecepatan upload maupun download merupakan dua hal yang sangat penting untuk memperlancar transmisi data. Banyak hal yang dapat mempengaruhi kecepatan dua proses 
tersebut, diantaranya yaitu besarnya bandwidth yang digunakan jaringan tersebut dan seberapa efektif bandwidth tersebut bisa dimanfaatkan. Bandwidth adalah suatu penghitungan konsumsi data yang tersedia pada suatu telekomunikasi. Dihitung dalam satuan bits per seconds/bps, menurut Surya dalam (Prawito \& Rhohman, 2017).

Menurut lqbal $M$ dalam (Anam \& Nurdiana, 2019) Manajemen bandwidth adalah besaran yang menunjukkan seberapa banyak data yang dapat dilewatkan dalam koneksi melalui sebuah network.

Hotspot adalah suatu koneksi jaringan secara wireless atau tanpa kabel yang siap digunakan dengan perangkat Wireless Local Area Network yang cocok(Ardianto, Alfaresi, \& Yuansyah, 2018). Jumlah user yang menggunakan hotspot sangat dinamis, dalam satu waktu bisa sampai 30 user menggunakn layanan internet tersebut dengan berbagai aktivitas download dan upload. Tidak adanya pengelolaan user yang menggunakan layanan internet mengakibatkan user hotspot akan terganggu dengan user lain. Koneksi internet yang stabil sangat diharapkan agar tamu nyaman ketika datang ke hotel dan menggunakan layanan internet.

Penelitian yang dilakukan oleh (Malik, Aksara, \& Yamin, 2017) manajemen bandwidth bisa dilakukan dengan simple queue dan queue tree. Metode queue tree merupakan metode yang sangat rumit karena limit bandwidth diatur berdasarkan protokol, ports, IP address. Tidak hanya itu, bahkan kita perlu mengaktifkan fitur Mangle di Firewall.

Dari penjelasan diatas, penelitian ini menggunakan metode simple queue di filter berdasarkan jenis user profiles yang akan menggunakan layanan internet. Serta jaringan yang dikonfigurasi termasuk skala menengah dan cocok untuk diterapkan. Batasan masalah yang akan diuraikan di penelitian ini yaitu objek penelitian di Hotel Ramayana Tasikmalaya, fokus penelitian pada manajemen user dan bandwidth dengan menggunakan router mikrotik, user yang menggunakan layanan hotspot yaitu tamu (menginap dan tidak menginap) dan karyawan hotel.

Router mikrotik merupakan salah satu vendor perangkat keras dan perangkat lunak yang salah satunya membuat router. Berisi sistem operasi yang khusus digunakan untuk konfigurasi jaringan komputer (Didi Susianto, 2016).

\section{Metode Penelitian}

Metode yang digunakan untuk pengembangan jaringan yaitu Network Development Life Cycle (NDLC) yang terdiri dari beberapa tahapan yaitu Analysis, Design, Simulation Prototyping, Implementation, Monitoring, Management (Aji \& Kharisma, 2019). Berikut penjelasan mengenai tahapan tersebut (Harun Sujadi, 2017):

\section{Analysis}

Merupakan tahapan awal yang berisi analisa permasalahan dan analisa topologi jaringan yang ada di Hotel Ramayana Tasikmalaya.

2. Design

Tahapan ini digambarkan dengan arsitektur jaringan yang sedang berjalan dan skema arsitektur jaringan yang di usulkan.

3. Simulation Prototyping

Tahap ketiga sebagai bentuk simulasi jaringan yang diusulkan pada tahapan sebelumnya maka arsitektur jaringan dibuat menggunakan perangkat lunak Cisco Packet Tracer. Setiap perangkat dikonfigurasi agar bisa saling terhubung walaupun hanya dalam simulasi. Sehingga bisa memberikan gambaran pada perangkat yang sesungguhnya.

4. Implementation

Tahapan ini merupakan identifikasi perangkat dan kebutuhan lain yang diperlukan untuk menerapkan rancangan arsitektur jaringan yang sebelumnya diusulkan. Selanjutnya dilakukan instalasi konfigurasi perangkat jaringan dan instalasi perangkat keras jaringan.

\section{Monitoring}

Tahap kelima dilakukan pengujian terhadap infrastruktur yang telah diimplementasikan apakah sudah sesuai harapan atau tidak.

\section{Management}

Tahapan ini digunakan untuk mengatur policy atau kebijakan agar sistem bisa berjalan sesuai aturan yang ada.

Selanjutnya untuk manajemen bandwidth menggunakan Simple Queue yang merupakan salah satu fitur di Mikrotik untuk melakukan manajemen bandwidth di skenario jaringan yang sederhana, pada Simple Queue pengaturan packet classification dan marking packet tidak wajib dilakukan (Prawito \& Rhohman, 2017). Simple queue melimit bandwidth berdasarkan data rate, dan mengatur pemakaian bandwidth upload dan download setiap user, antrian harus di selalu dikonfigurasi pada interface keluar arus lalu lintas data (Towidjojo, 2014).

Topologi yang digunakan pada jaringan ini menggunakan Topologi Star, dimana jaringan membentuk seperti bintang karena semua perangkat dihubungkan ke switch dengan kabel UTP, sehingga switch merupakan pusat dari jaringan dan bertugas mengontrol 
lalu lintas data (Ontoseno, Haqqi, \& Hatta, 2017).

\section{Hasil dan Pembahasan}

Pada kondisi awal, Hotel Ramayana Tasikmalaya menggunakan internet dari Telkom (Indihome) dengan bandwidth $20 \mathrm{Mbps}$, internet untuk tamu diberikan menggunakan hotspot atau Access Point di lima titik. Access Point merupakan perangkat jaringan yang berisi sebuah transceiver dan antena untuk transmisi dan menerima sinyal ke dan dari client (Novrianda Dasmen, 2018).

Access Point berfungsi sebagai pengatur lalu lintas daya, sehingga banyak client bisa terhubung melalui jaringan (Limantara, Candra, \& Mudjanarko, 2017). Dan sisanya ada empat komputer yang terkoneksi jaringan.

Hasil dari analisis upload dan download yang dilakukan terdapat kekurangan dari jaringan yang ada diantaranya jika salah satu client melakukan proses download maka penggunaan bandwidth akan terfokus di client tersebut sehingga jaringan menjadi tidak stabil dan penggunaan bandwidth tidak merata terbagi ke client yang sedang aktif. Router Modem yang ada tidak terdapat fitur untuk manajemen bandwidth.



Sumber : Hasil Penelitian (2020)

Gambar 1. Router Modem

Berdasarkan permasalahan tersebut diatas, untuk menambah kapasitas bandwidth maka bandwidth di upgrade ke 40 Mbps yang nantinya akan digunakan untuk layanan hotspot dan perangkat komputer. Selanjutnya perlu ditambah nya perangkat router dalam hal ini router Mikrotik sebagai alat untuk manajemen bandwidth. Dalam mikrotik router memiliki fitur Quality of Services salah satunya Simple Queue. Hal yang ingin dicapai di pengembangan jaringan ini yaitu router mikrotik harus bisa membuat username dan password yang nantinya digunakan untuk layanan hotspot untuk tamu dan karyawan, selanjutnya router mikrotik harus bisa mengatur bandwidth untuk client yang terhubung ke hotspot dan yang terhubung menggunakan jaringan kabel.



Sumber : Hasil Penelitian (2020)

Gambar 2. Topologi Jaringan Lama 


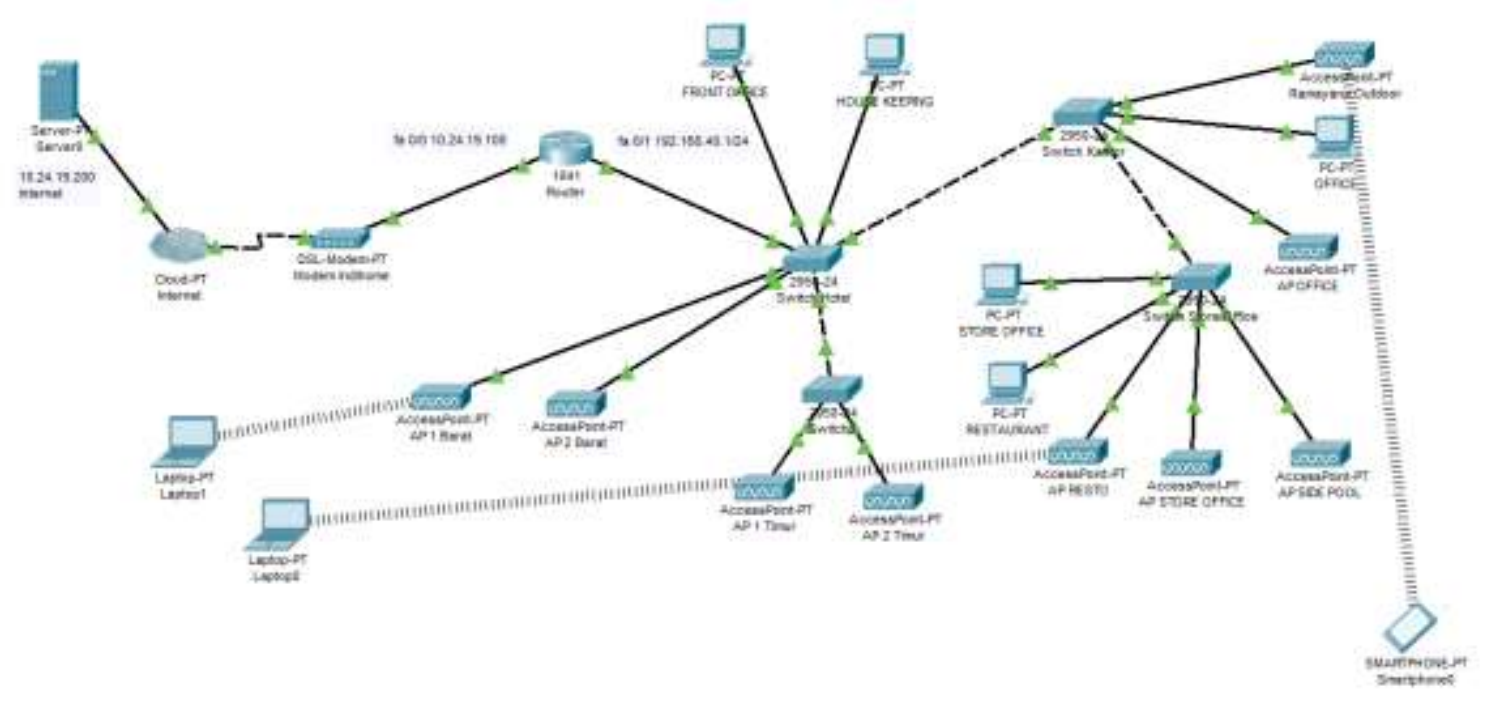

Sumber : Hasil Penelitian (2020)

Gambar 3. Topologi Jaringan Baru

Pada desain topologi yang baru terdapat perbedaan penambahan Mikrotik Router, penambahan perangkat Access Point dan perangkat komputer.

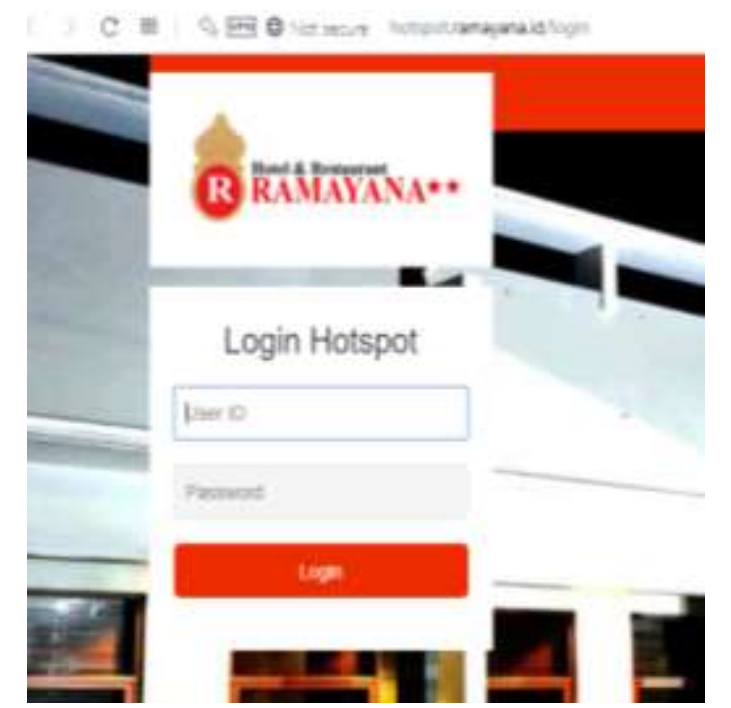

Sumber : Hasil Penelitian (2020)

Gambar 4. Tampilan form login hotspot
Untuk router mikrotik menggunakan RB951G-2HnD dan pada tahap ini dilakukan juga manajemen bandwidth untuk user yang akan menggunakan layanan internet. Seperti terlihat pada gambar dibawah ini:

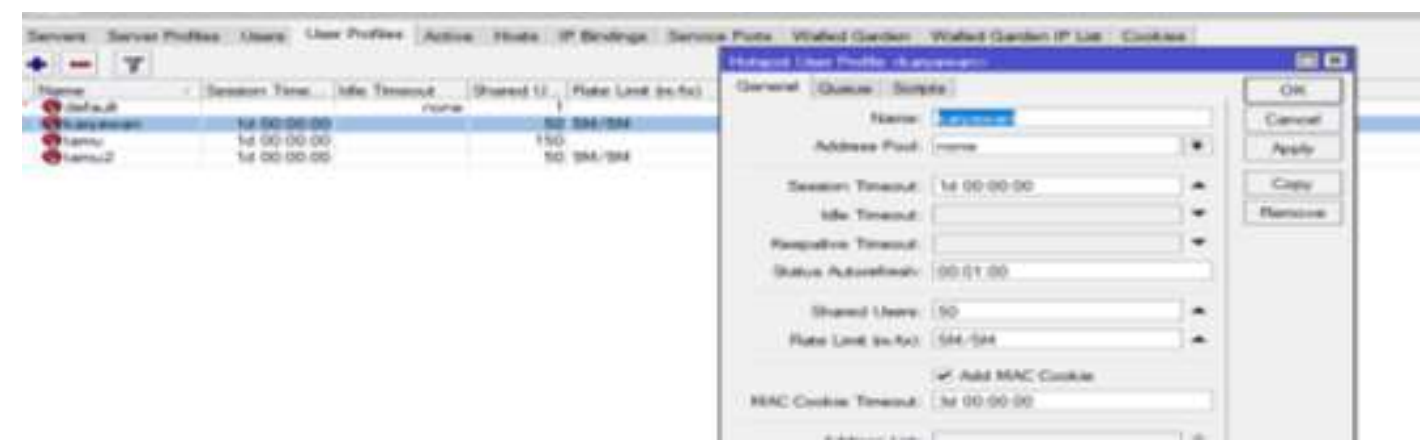

Sumber : Hasil Penelitian (2020)

Gambar 5. Manajemen Limitasi Bandwidth 


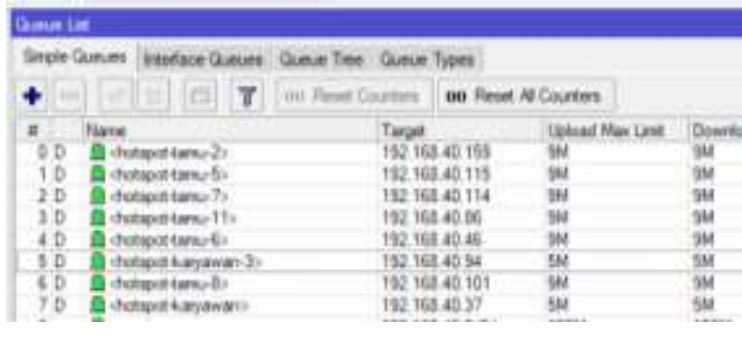

Sumber : Hasil Penelitian (2020)

Gambar 6. Simulasi Hasil Manajemen

Limitasi Bandwidth di Simple Queue

Selanjutnya setiap konfigurasi diimplementasikan sesuai kebutuhan yang diinginkan selanjutnya diuji apakah konfigurasi sudah sesuai dengan yang direncakan dari hasil pengujian yang didapat bahwa manajemen bandwidth bisa berjalan dengan baik dibandingkan di konfigurasi lama. Semua konfigurasi termasuk mengatur bandwidth, user dan simple queue diatas menggunakan perangkat lunak Winbox yang berbasis GUI Interface <bridge-hotspot> Statistics

- Last usdate: Thu Mar 12 11:47:08 2020

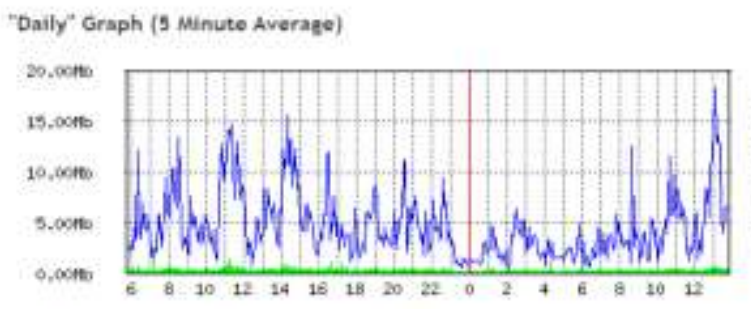

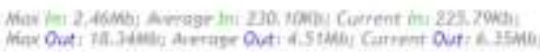

(Graphical User Interface) sehingga lebih mudah dalam proses konfigurasi di router mikrotik termasuk mengatur router secara jarak jauh atau remote, yang dikoneksikan menggunakan MAC Address atau IP Address(Hidayat, 2018). Berikut merupakan hasil monitoring penggunaan bandwidth selama 1 hari dan 1 minggu, menggunakan fitur Graph dari mikrotik dari hasil grafik terlihat bahwa penggunaaan bandwidth masih terdapat banyak sisa dan tidak mengalami full bandwidth, rata-rata maksimal penggunaan 20 Mbps. Untuk pengujian throughput yang diterima oleh user menggunakan internet speed test dari web https://speedtest.cbn.id. Throughput merupakan jumlah data per satuan waktu yang dikirim untuk suatu terminal tertentu di dalam sebuah jaringan, dari satu titik jaringan, atau dari satu titik ke titik jaringan yang lain (Aswariza, Perdana, \& Negara, 2017).

Sumber : Hasil Penelitian (2020)

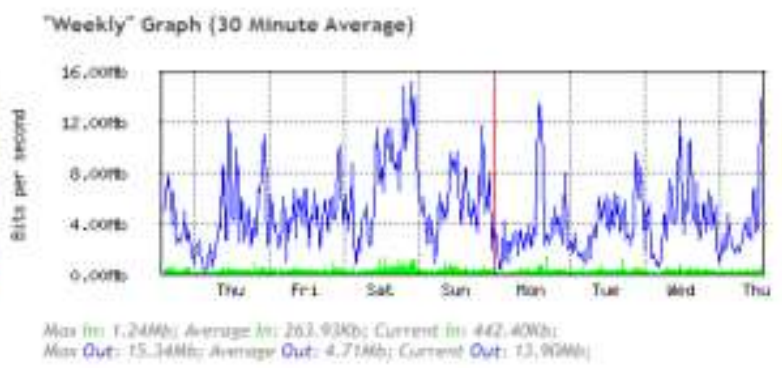

Gambar 7. Bandwidth Graph



Sumber : Hasil Penelitian (2020)

Gambar 8 Hasil Speedtest Limitasi User

Pengecekan secara rutin terhadap konfigurasi jaringan dan penambahan perangkat yang baru terus dilakukan, untuk antisipasi gangguan dan perbaikan kendala yang ada sehingga perangkat bisa beroperasi dengan baik. 


\section{Kesimpulan}

Berdasarkan penelitian yang telah dilakukan bahwa sebelum diterapkan manajemen user dan metode pengaturan bandwidth, client yang menggunakan layanan hotspot mendapatkan kualitas bandwidth yang tidak sesuai karena tidak adanya manajemen user dan pembagian bandwidth antar pemakai hotspot. Serta perangkat keras yang digunakan hanya masih menggunakan router dari penyedia layanan internet. Setelah adanya penambahan perangkat router mikrotik dan penerapan manajemen user dan bandwidth maka client yang akan terhubung ke layanan hotspot diharuskan login dengan user dan password yang sudah disediakan, mikrotik router berperan dalam melakukan limitasi bandwidth simple queue pada user hotspot tersebut, sehingga setiap client dipastikan mendapatkan alokasi IP Address dan bandwidth yang stabil.

\section{Referensi}

Aji, S. W., \& Kharisma, R. S. (2019). Manajemen User Dan Pengelolaan Bandwidth Pada Jaringan Hotspot Menggunakan Router Mikrotik. Information Tehnology Journal, 1(2), 1-5.

Anam, Y. S., \& Nurdiana, N. (2019). Optimalisasi Manajemen Bandwidth Jaringan Komputer Dengan Metode PCQ (Peer Connection Queue) Menggunakan Simple Queue. Proceedings - STMA 4.0, 53-57. Retrieved from https://prosiding.unma.ac.id/index.php/sti $\mathrm{ma} /$ article/view/277

Ardianto, F., Alfaresi, B., \& Yuansyah, R. A. (2018). Jaringan Hotspot Berbasis Mikrotik Menggunakan Metode Otentikasi Pengguna. Jurnal Surya Energy, 2(2), 167. Retrieved from https://jurnal.umpalembang.ac.id/senergi/article/view/103 2/895

Aswariza, R. F., Perdana, D., \& Negara, R. M. (2017). Analisis Throughput Dan Skalabilitas Virtualized Network Function VyOS Pada Hypervisor VMWare ESXi, XEN, DAN KVM. Jurnal Infotel, 9(1), 70. https://doi.org/10.20895/infotel.v9i1.173

Didi Susianto. (2016). Implementasi Queue Tree Untuk Manajemen Bandwidth Menggunakan Router Board Mikrotik. Cendikia, 12(1), 7.

Harun Sujadi, A. M. (2017). Rancang Bangun Arsitektur Jaringan Komputer Teknologi Metropolitan Area Network (Man) Dengan Menggunakan Metode Network Development Life Cycle (Ndlc). J-Ensitec, 4(1), 142-146. Retrieved from http://www.jurnal.unma.ac.id/index.php/J
E/article/view/682

Hidayat, A. (2018). Design of Radius Server on Server Network Internet Faculty of Computer Science University Muhammadiyah Metro. International Journal Information System and Computer Science (IJISCS), 2(1), 13-29. Retrieved from https://ojs.stmikpringsewu.ac.id/index.php /ijiscs/article/download/547/499

Kemp, S. (2020). DIGITAL 2020: INDONESIA. Retrieved March 5, 2020, from https://datareportal.com/reports/digital2020-indonesia

Limantara, A. D., Candra, A. ., \& Mudjanarko, S. W. (2017). Manajemen Data Lalu Lintas Kendaraan Berbasis Sistem Internet Cerdas Ujicoba Implementasi di Laboratorium Universitas Kadiri. Pros. Semnastek, 4(November), 1-11. Retrieved from https://jurnal.umj.ac.id/index.php/semnast ek/article/view/1808/1486

Malik, A., Aksara, L. F., \& Yamin, M. (2017). Perbandingan Metode Simple Queues Dan Queues Tree Untuk Optimasi Manajemen Bandwidth Menggunakan Mikrotik (Studi Kasus: Pengadilan Tinggi Agama Kendari). SemanTIK, 3(2), 1-8.

Novrianda Dasmen, R. (2018). Implementasi Raspberry Pi 3 Sebagai Wireless Access Point Pada STIPER Sriwigama Palembang. Jurnal Informatika: Jurnal Pengembangan IT, 3(3), 387-393. https://doi.org/10.30591/jpit.v3i3.943

Ontoseno, R. D. H., Haqqi, M. N., \& Hatta, M. (2017). Limitasi Pengguna Akses Internet Berdasarkan Kuota Waktu Dan Data Menggunakan Pc Router Os Mikrotik. Teknika: Engineering and Sains Journal, 1(2), 125-130. https://doi.org/10.5281/zenodo.1116499

Prawito, A., \& Rhohman, F. (2017). Manajemen Bandwidth Menggunakan Simple Queue Pada Mikrotik Di SMK PGRI 1 Kota Kediri. Tecnoscienza, 1(2), 1-10. Retrieved from http://ejournal.kahuripan.ac.id/index.php/ TECNOSCIENZA/article/view/15

Towidjojo, R. (2014). Mikrotik Kung Fu Kitab 2 Kitab Manajemen Bandwidth. Palu: Jasakom.

Yasin K. (2018). Pengertian Bandwidth dan Fungsinya (Lengkap). Retrieved November 23, 2020, from https://www.niagahoster.co.id/blog/penge rtian-bandwidth/\#: : :text=Bandwidth adalah kapasitas yang dapat,bit per second (bps). 